\title{
A Celebration of Both Quantity AND Quality: Symposium Honors the Prolific Career of Randall M. German
}

\section{Lynne Robinson}

Editor's Note: The following was excerpted from a more detailed article posted on Materials Technology@TMS at materialstechnology.tms.org/EST larticle.aspx?articlelD $=4248$

It is a rare opportunity to help shape an industry in its nascent stages of development. But that's exactly what was presented to Randall German about a year after receiving his undergraduate degree from San Jose State University. As a young materials scientist with Battelle Columbus Laboratories, he was one of a very few people at the time to have gained any experience in powder metallurgy - an area that was just starting to be of interest in the manufacture of aerospace components. Sandia National Laboratories, California, became aware of his expertise, and said German, "Offered me the opportunity to convert a warehouse into a powder metallurgy lab. I couldn't believe that I was being asked to build a lab with a year's experience." German then spent the next six months "visiting everyone in the field," launching what was to become one of the most influential and productive scientific journeys in sintering and powder-based materials.

"Rand's work in powder metallurgy has more or less defined and led that field," said Burton (Pat) Patterson, research scientist, University of Florida, and a long-time colleague of German's. "Rand is the most productive researcher, prolific writer, and entrepreneurial scientist I have ever seen. I have always admired his ability to do so much and produce such thorough, high-quality, authoritative work. I don't know how he does it, but he's alone in his ability to do so much so well."

To celebrate German's prolific and pioneering contributions over the last 40 years, the TMS Powder Materials Committee and Materials Processing

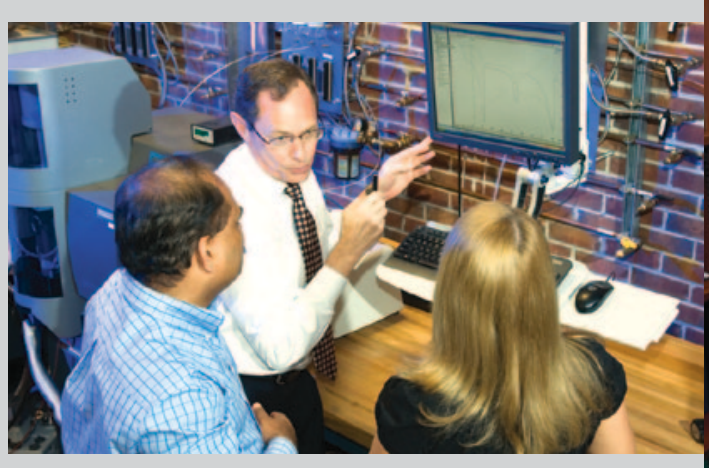

(Photo left) Randall German works with students in the thermal analysis laboratory. German (photo right) has supervised more than 100 graduate students alone, joking, "I won't ever get strandedThere is probably a former student of mine in every major metropolitan area in the world."

\& Manufacturing Division have organized the Randall M. German Honorary Symposium on Sintering and Powder-Based Materials for the TMS 2012 Annual Meeting and Exhibition, March 11-15, in Orlando, Florida.

"It is very hard to think of sintering and particulate materials processing and not mention his name," said K. Morsi, professor, San Diego State University, and symposium organizer. "I hope the symposium brings across the scientific contributions of Professor German within the context of sintering as a field, while also highlighting his life-long commitment to its industrial implications. This type of awareness is not often seen."

German, now associate dean of engineering and professor of mechanical engineering, San Diego State University, bolstered his naturally entrepreneurial spirit with formal business training, completing management programs at both Harvard University and Rensselaer Polytechnic Institute, where he also served as the Hunt Professor of Materials Engineering. This background served him well in making the most of "phenomenal opportunities," including establishing the Center for Innovative Sintered Products at Penn State University as the Brush Chair
Professor in Materials and serving as the director, Center for Advanced Vehicular Systems at Mississippi State University. Along the way, he helped ignite an explosion of research and advancement in powder processing. Said Eugene A. Olevsky, symposium organizer and Distinguished Professor of Mechanical Engineering, San Diego State University, "According to Thomson Reuters ISI Web of Knowledge, Randall German is one of the world's most frequently cited researchers, and he is the most productive author, in all of history, in the area of powder sintering, He has authored nearly 1000 publications, 24 patents, and 16 books, including the most well-known textbooks on sintering, injection molding, and other fields related to core powder processing technologies. In the field of powder processing, he established a whole school of ideas and approaches that are being further explored by his former and current students and collaborators."

German fully intends to be part of that exploration, both now and in the future. With book \#17 in the works, he noted that his passion for his work is rooted in a pretty fundamental motivator: "I just really enjoy doing this sort of stuff." 